\title{
Decalcifying efficacy of different irrigating solutions: effect of cetrimide addition
}

\section{Claudio POGGIO \\ Alberto DAGNA \\ MarCO COLOMBO \\ Andrea SCRIBANTE \\ Marco CHIESA}

Department of Clinical, Surgical, Diagnostic and Pediatric Sciences, Section of Dentistry, University of Pavia, Pavia, Italy.
Declaration of Interests: The authors certify that they have no commercial or associative interest that represents a conflict of interest in connection with the manuscript.

Corresponding Author:

Claudio Poggio

E-mail: claudio.poggio@unipv.it

DOI: 10.1590/1807-3107BOR-2014.vol28.0047

Submitted: Feb 04, 2014

Accepted for publication: May 22, 2014

Last revision: Aug 18, 2014
Abstract: The objective of the present study was to evaluate and compare the influence of cetrimide on decalcifying capability of different irrigating solutions. Fifteen maxillary central incisor teeth has been collected. The canals were prepared in order to obtain four samples from each root. The specimens were randomly divided into 6 experimental groups $(n=10)$ according to tested irrigating agents. Irrigating agents consisted in different composition of EDTA and citric acid solutions, addicted or not with cetrimide. Each specimen was submitted to three successive 5-min immersions in each solution. After exposures, the concentration of $\mathrm{Ca} 2+$ extracted was measured by inductively coupled plasma-atomic emission spectrometry (ICP-AES). Data were analysed by means of Kruskal Wallis and Mann Whitney tests. Significance was predetermined at $\mathrm{p}<0.05$. For all irrigants, the amounts of $\mathrm{Ca} 2+$ extracted from root canal dentin samples at 10 minutes were not significantly different from values reported after 15 minutes respectively. Therefore, for all irrigants tested, 10 minutes of application are sufficient to obtain maximum $\mathrm{Ca} 2+$ release. Moreover citric acid based agents observed a higher release of $\mathrm{Ca} 2+$. The addition of cetrimide did not affect the decalcifying capability of the EDTA and citric acid solutions.

Keywords: Chelating Agents; Dentin; Dentistry; Endodontics.

\section{Introduction}

During biomechanical instrumentation of root canals an amorphous layer (smear layer) of organic and inorganic debris and, in cases of contamination, of bacterial component is formed. This layer can be deposited along the canal walls, ${ }^{1,2,3,4}$ thus reducing sealer adhesion and negatively affecting the sealing. ${ }^{5}$ Therefore it should be removed before obturation, to ensure a close contact of the sealer with the dentin surface. To eliminate the smear layer, irrigants able to dissolve both organic and inorganic components could be applied.

Chelating agents are believed to aid root canal irrigation and to be able to remove the inorganic smear layer; ${ }^{5}$ the addition of sodium hypochlorite $(\mathrm{NaOCl})$ could improve the efficacy of the chelating agent on dissolving the organic fraction of the smear layer. ${ }^{4}$ In particular, the selected irrigating solutions showed direct action over calcium present in hydroxyapatite crystals of dentin. Any change in the calcium ratio can significantly modify the original proportion of organic and inorganic components. This can alter dentin permeability, microhardness and solubility. ${ }^{6}$ Although 
EDTA presents a long-standing history because it is the most frequently recommended solution for the removal of the smear layer in endodontics, previous studies demonstrated its irritating potential. ${ }^{7,9,10} \mathrm{In}$ order to to remove the inorganic component of root dentin, other substances have been suggested. Citric acid at concentration ranging from $5 \%$ to $50 \%$, apple vinegar and phosphoric acid at different concentrations ${ }^{11,12,13,14}$ has been proposed with different percentages of success. ${ }^{6,8,9,14}$ MTAD $^{10}$ and, recently, Tetraclean ${ }^{15,16}$ have been investigated as new irrigating solutions based on a mixture of citric acid and antibiotics (tetracycline isomer). These solutions have been proposed as detergent for the final rinse of surfaces of instrumented root canals. MTAD and Tetraclean differ in doxycycline concentration (150 $\mathrm{mg} / 5 \mathrm{ml}$ for MTAD and $50 \mathrm{mg} / 5 \mathrm{ml}$ for Tetraclean) and in the type of detergent (Tween 80 for MTAD, polypropylene glycol for Tetraclean). Cetrimide (cetyltrimethylammonium bromide) is a cationic surfactant. Cetrimide is a quaternary ammonium compound and a cationic detergent that is effective against many Gram-positive and Gram-negative bacteria. Many products contain cetrimide, because its addiction improves efficacy of irrigating solutions: cationic surfactants have been reported to have bactericidal and fungicidal properties. ${ }^{17,18}$ Many studies reported the ability of chelating solutions to reduce or eliminate the smear layer, but no reports evaluated concentration of calcium ions removed from teeth with different chelators. ${ }^{19}$

Accordingly, the objective of the present study was to evaluate and compare the influence of cetrimide on decalcifying capability of different irrigating solutions. Calcium extracted from root canal dentin has been measured at three immersion times $(5,10$ and 15 minutes respectively). The null hypothesis of the study was that there is no significant difference in concentration of calcium extracted among the various groups.

\section{Methodology}

Fifteen maxillary central incisor, recently extracted for peridontal reasons, were stored in $0,1 \%$ tymol solution until use. The crowns were removed at cemento-enamel junction using an Accutom-50 diamond cutter (Accutom
Hard Tissue Microtome, Struers, Ballerup, Denmark) under water-cooling. The root surface was treated with a low speed fine-grain diamond bur (Perio-Set, Intensiv, Grancia, Switzerland) under abundant irrigation in order to remove the root cementum. Root canals were instrumented with Peeso burn $n^{\circ} 4$ to 6 under irrigation (Dentsply Maillefer, Ballaigues, Switzerland) using an handpiece. After each instrument, the root canal was irrigated with $5 \mathrm{ml}$ of distilled water. Two transversal sections of 2-mm thickness were obtained from the cervical third of each root using a pre-programmed automatic Accutom-50 diamond cutter (Accutom Hard Tissue Microtome, Struers, Ballerup, Denmark). Each slice was then sectioned in four equal sections, obtaining a total of four (s1, s2, s3, s4) samples from each root. To yield each sample with same calcification, geometry and weight the samples were weighted on a HM 202 precision balance (A\&D Engineering Inc., San Jose, USA) and, when necessary, equalized their weight with disks of 600-grit silicon-carbide paper, always removing from the central part of the section to avoid modification of the geometry.

This method allows testing irrigating solution decalcifying capacity on comparable specimens. Samples were then catalogued and stored into distilled water at room temperature. The specimens were then assigned to one of 6 experimental groups $(\mathrm{n}=$ 10) for treatment with different irrigating solutions, as follows: group 1: EDTA 15\%, group 2: EDTA 15\% + cetrimide 1\%, group 3: EDTA 17\%, group 4: EDTA $17 \%+$ cetrimide $1 \%$, group 5 : citric acid $10.5 \%$, group 6: citric acid $10.5 \%$ + cetrimide $1 \%$.

The solutions were prepared in laboratory using analytical pure grade reagents. In particular EDTA solutions were prepared by dissolving the opportune quantity of EDTA disodium salt (Sigma-Aldrich, Milan, Italy) in ultrapure water, favouring dissolution with the addition of sodium hydroxide $40 \%$ and adding 1 $\mathrm{M}$ hydrochloric acid to obtain a final $\mathrm{pH}$ around 7 . Citric acid solutions were obtained by dissolving the opportune quantity of citric acid (Sigma- Aldrich, Milan, Italy) in ultrapure water, favouring dissolution with the addition of sodium hydroxide $40 \%$ and adding $1 \mathrm{M}$ hydrochloric acid to obtain a final $\mathrm{pH}$ around 7. Citric acid solutions were obtained by dissolving the opportune quantity of citric acid (SigmaAldrich, Milan, Italy) in ultrapure water. Cetrimide 
1\% (CH3 $(\mathrm{CH} 2) 15 \mathrm{~N}(\mathrm{Br})(\mathrm{CH} 3) 3$ / Panreac, Barcelona, Spain) was added to the EDTA or citric acid solutions.

The $\mathrm{pH}$ of each solution was determined by using a PHM 84 Research pH meter (Radiometer, Copenhagen, Denmark) and a combined ORION glass electrode (Thermo Electron Corp, Waltham, USA). The accuracy of the $\mathrm{pH}$ meter was \pm 0.01 . In order to determinate the initial calcium concentration in each irrigating agent, before the exposure to specimen, 5 $\mathrm{ml}$ of solution was analysed and the calcium content was taken as blank. Each specimen was immersed in $20 \mathrm{ml}$ of the correspondent irrigant solution and kept under constant stirring using a magnetic stirrer. At three successive 5 -min immersion times ( $\mathrm{t} 1=$ $5 \mathrm{~min}$; $2=10 \mathrm{~min}$; $3=15 \mathrm{~min}$ ), without renewing the solution, $5 \mathrm{ml}$ of irrigant was separated with a graduated pipette, and then placed in hermetically sealed and labelled tubes. An inductively coupled plasma atomic emission spectrometer (ICP-AES Perkin Elmer, Monza, Italy) was used for calcium determination in each solution. The linearity of the instruments is verified by analysing standard solutions in a concentration range between 0 and $100 \mathrm{mg} / \mathrm{l}$. The limit of detection (LOD) is $0.5 \mathrm{mg} / \mathrm{l}$, whereas the limit of quantification (LOQ) is $2.5 \mathrm{mg} / 1$. Data were analyzed using OriginPro 8 SRO software (Origin-
Lab Corporation, Northampton, USA). Descriptive statistics that included the mean, standard deviation, confidence limits for the mean and median, were calculated for each of the groups tested. The amount of calcium extracted (mg/1 Ca2+) by different irrigating solutions and in different immersion times was analyzed using Kruskal-Wallis test and Mann-Whitney tests. The level of statistical significance was predetermined at $p<0.05$.

\section{Results}

The efficacy of several irrigating solutions used to remove calcium from root dentin has been tested. Dentine specimens were immersed in each agent for 5, 10 and 15 minutes. For each test solution, descriptive statistics of the values of $\mathrm{Ca} 2+$ released from root dentin at different times were reported in Table 1. For each irrigating solution lowest amount of $\mathrm{Ca} 2+$ released was recorded after 5 minutes of application $(\mathrm{p}<0.05)$. No significant difference in amount of $\mathrm{Ca} 2+$ released was showed when comparing 10 and 15 minutes groups of each irrigating solution $(p>0.05)$. Moreover no significant differences were reported among groups $1,2,3$ and $4(\mathrm{p}>0.05)$, that all showed significantly lower $(\mathrm{p}<0.001)$ amount of calcium extracted than groups 5 and 6 , that showed

Table 1. Calcium released (mg/l) from root canal dentin after 5, 10, and 15 minutes treatment with tested irrigating solutions.

\begin{tabular}{|c|c|c|c|c|c|c|c|}
\hline $\begin{array}{l}\text { Application } \\
\text { time (min) }\end{array}$ & Irrigating solution & Mean & $\begin{array}{l}\text { Standard } \\
\text { Deviation }\end{array}$ & $\begin{array}{l}\text { Confidence limits } \\
\text { for the Mean }\end{array}$ & Minimum & Median & Maximum \\
\hline 5 & EDTA 15\% & 6.9 & 0.5 & 0.8 & 6.4 & 6.9 & 7.4 \\
\hline 10 & EDTA $15 \%$ & 8.8 & 0.4 & 0.7 & 8.3 & 8.75 & 9.3 \\
\hline 15 & EDTA 15\% & 9.2 & 0.6 & 0.9 & 8.3 & 9.4 & 9.6 \\
\hline 5 & EDTA $15 \%+$ Cetrimide $1 \%$ & 7.2 & 1.4 & 2.2 & 5.9 & 7.2 & 8.4 \\
\hline 10 & EDTA $15 \%+$ Cetrimide 1\% & 8.9 & 0.5 & 0.8 & 8.2 & 9 & 9.4 \\
\hline 15 & EDTA $15 \%$ + Cetrimide 1\% & 7.8 & 0.9 & 1.4 & 6.8 & 7.85 & 8.7 \\
\hline 5 & EDTA $17 \%$ & 6.4 & 0.5 & 0.6 & 6 & 6.4 & 7.2 \\
\hline 10 & EDTA $17 \%$ & 8.0 & 1.6 & 2.0 & 6.2 & 8.4 & 10.2 \\
\hline 15 & EDTA $17 \%$ & 8.0 & 0.7 & 0.9 & 7.1 & 8.3 & 8.7 \\
\hline 5 & EDTA 17\% + Cetrimide 1\% & 7.2 & 1.3 & 1.6 & 5.5 & 7.3 & 8.8 \\
\hline 10 & EDTA 17\% + Cetrimide 1\% & 9.0 & 1.8 & 2.3 & 6.5 & 9.2 & 11.1 \\
\hline 15 & EDTA 17\% + Cetrimide 1\% & 9.0 & 2.0 & 2.5 & 6.2 & 9.3 & 11.3 \\
\hline 5 & Citric acid $10.5 \%$ & 21.4 & 1.9 & 2.4 & 18.6 & 21.4 & 23.6 \\
\hline 10 & Citric acid $10.5 \%$ & 27.3 & 2.1 & 2.6 & 24.8 & 28.1 & 29.4 \\
\hline 15 & Citric acid $10.5 \%$ & 27.2 & 2.4 & 3.0 & 24 & 28.1 & 30 \\
\hline 5 & Citric acid $10.5 \%+$ Cetrimide $1 \%$ & 16.9 & 3.1 & 3.9 & 11.6 & 18.1 & 19.6 \\
\hline 10 & Citric acid $10.5 \%+$ Cetrimide $1 \%$ & 23.7 & 2.8 & 3.5 & 19.3 & 23.6 & 27 \\
\hline 15 & Citric acid $10.5 \%+$ Cetrimide $1 \%$ & 24.2 & 3.1 & 3.8 & 20 & 24.2 & 28.5 \\
\hline
\end{tabular}


no significant difference between them ( $p>0.05)$. Results are reported in Table 2 .

The amount of calcium extracted (mg/1 Ca2+ mean value of 5 replicates) with five irrigating solutions at different immersion times is reported in Figure. The error bars represent the SD.

\section{Discussion}

The null hypothesis of the study has been rejected. A significantly higher release of $\mathrm{Ca} 2+$ was observed in samples submitted to citric acid based agents. The amount of $\mathrm{Ca} 2+$ extracted from root dentin samples for all irrigating solutions at 10 minutes did not show signifi-

Table 2. Comparison of calcium released $(\mathrm{mg} / \mathrm{l})$ from root canal dentin after 10 and 15 minutes treatment with tested irrigating solutions: results of the Mann-Whitney test.

\begin{tabular}{|c|c|c|c|c|c|}
\hline Application time (min) & Irrigating solution & Mean & $\begin{array}{l}\text { Standard } \\
\text { Deviation }\end{array}$ & Median & $\begin{array}{c}\text { Mann-Whitney Test (at } 0.05 \text { level) } \\
\text { probability value }(p)\end{array}$ \\
\hline 10 & EDTA 15\% & 8.8 & 0.4 & 8.75 & \multirow{2}{*}{$0.3065>0.05$} \\
\hline 15 & EDTA $15 \%$ & 9.2 & 0.6 & 9.4 & \\
\hline 10 & EDTA 15\% + Cetrimide 1\% & 8.9 & 0.5 & 9 & \multirow{2}{*}{$0.1123>0.05$} \\
\hline 15 & EDTA $15 \%+$ Cetrimide $1 \%$ & 7.8 & 0.9 & 7.85 & \\
\hline 10 & EDTA $17 \%$ & 8.0 & 1.6 & 8.4 & \multirow{2}{*}{$0.8345>0.05$} \\
\hline 15 & EDTA $17 \%$ & 8.0 & 0.7 & 8.3 & \\
\hline 10 & EDTA $17 \%+$ Cetrimide $1 \%$ & 9.0 & 1.8 & 9.2 & \multirow{2}{*}{$0.9166>0.05$} \\
\hline 15 & EDTA $17 \%+$ Cetrimide $1 \%$ & 9.0 & 2.0 & 9.3 & \\
\hline 10 & Citric acid $10.5 \%$ & 27.3 & 2.1 & 28.1 & \multirow{2}{*}{$0.9163>0.05$} \\
\hline 15 & Citric acid $10.5 \%$ & 27.2 & 2.4 & 28.1 & \\
\hline 10 & Citric acid $10.5 \%+$ Cetrimide $1 \%$ & 23.7 & 2.8 & 23.6 & \multirow{2}{*}{$1.000>0.05$} \\
\hline 15 & Citric acid $10.5 \%+$ Cetrimide $1 \%$ & 24.2 & 3.1 & 24.2 & \\
\hline
\end{tabular}

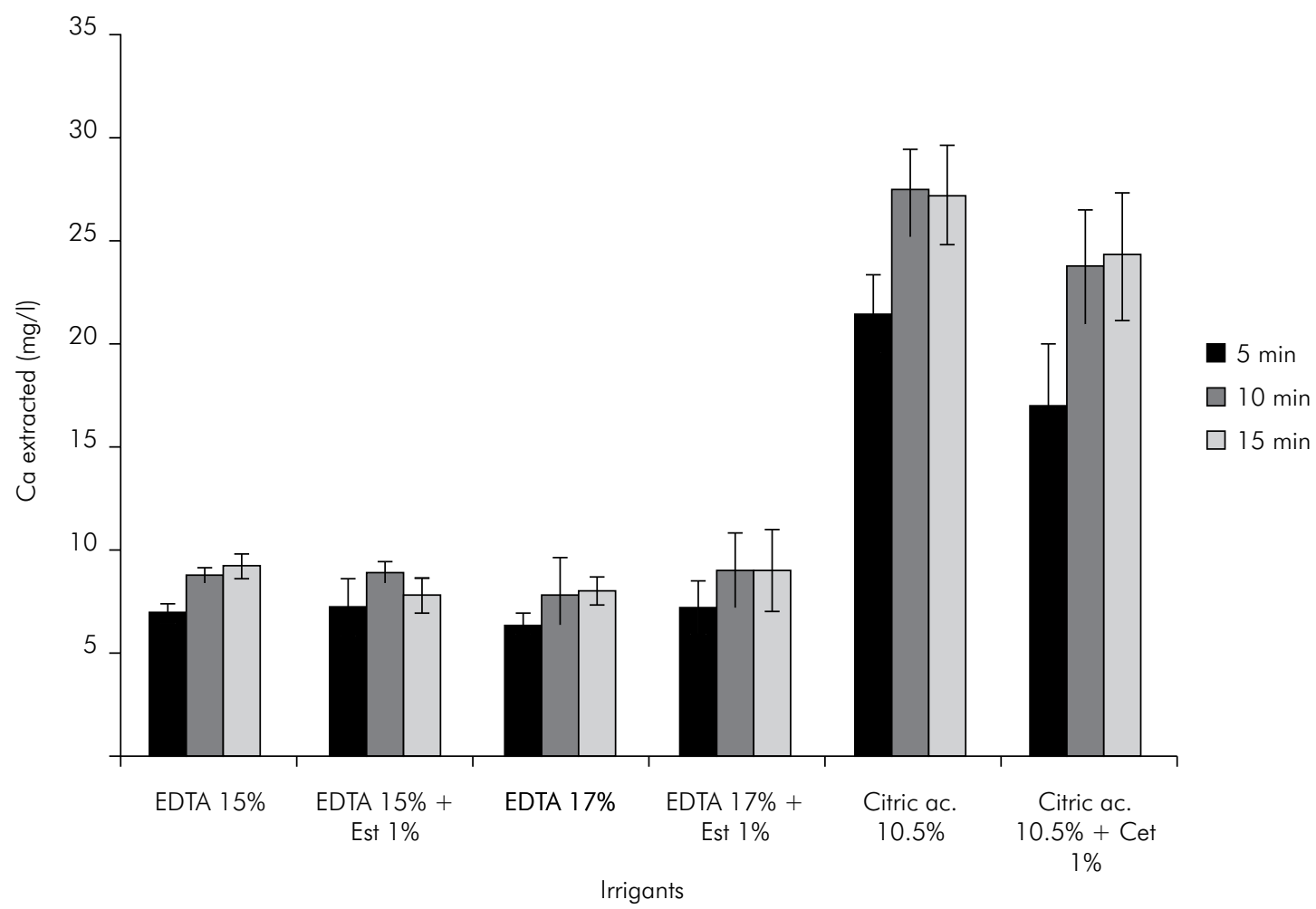

Figure. Amount of calcium extracted (mg/l $\mathrm{Ca} 2+-$ mean value of 5 replicates) with five irrigating solutions at different immersion times. The error bars represent the SD. 
cant differences when compared to the values reported at 15 minutes. Therefore in the present investigation an application of 10 minutes is sufficient to reach the maximum release of $\mathrm{Ca} 2+$ for all irrigating solutions tested. Results are in agreement with those obtained by other Authors $^{14}$ that compared the decalcifying effect of $15 \%$ EDTA and 15\% citric acid on root canal dentine. They analysed the amount of calcium extracted from dentin samples by atomic absorption spectrophotometry and obtained similar results at three immersion times, with no significant differences between EDTA and citric acid. They observed no significant differences between 10-min and 15-min immersion. This could be explained, in relation to the acid and chelating solution studied, by an increase in the organic material exposed on root dentin surface after action of the demineralizing agents. The organic matrix of dentine may act as a limiting factor in the dissolution of the inorganic component, thus reducing the decalcifying action of chelating agents over time. ${ }^{14}$ Higher release in this study can be due to the lower $\mathrm{pH}$ of the citric acid solutions $(\mathrm{pH}<2)$, thus increasing the removal of major inorganic elements such as calcium present in the hydroxyapatite crystals. This is in agreement with previous results. ${ }^{6}$ Moreover, another investigation ${ }^{20}$ reported that the $\mathrm{pH}$ of citric acid solution is a more important factor than concentration in demineralisation test. Authors reported that this could be due to a balance between the decrease in $\mathrm{pH}$ and the increase in viscosity of the solution caused by the increase in the constituent concentration. In fact at high citrate concentrations, the quantity of $\mathrm{Ca} 2+$ released is dramatically reduced. The addition of $1 \%$ cetrimide did not affect

\section{References}

1. Doğan H, Qalt S. Effect of chelating agents and sodium hypochlorite on mineral content of root dentin. J Endod. 2001 Sep;27(9):578-80.

2. Hennequin M, Pajot J, Avignant D. Effect of different $\mathrm{pH}$ values of citric acid solutions on the calcium and phosphorus contents of human root dentin. J Endod. 1994 Nov;20(11):551-4.

3. Sen BH, Wesselink PR, Turkun M. The smear layer: a phenomenon in root canal therapy. Int Endod J. 1995 May;28(3):141-8.

4. Sim TP, Knowles JC, Ng YL, Shelton J, Gulabilava K. Effect of sodium hypochlorite on mechanical properties of dentine and tooth surface strain. Int Endod J. 2001 Mar;34(2):120-32. the extraction properties of the EDTA and citric acid solutions because the values of concentration of $\mathrm{Ca} 2+$ released in the two solutions did not significantly differ. Cationic surfactants are potent antimicrobial agents that have also been shown to act on biofilm components, but they have no decalcifying effects on root canal dentin. ${ }^{20}$ The results here presented indicate that, to obtain an efficient removing of the smear layer and to facilitate the biomechanical procedures, citric acid based agents can be applied and cetrimide can help in improving efficacy of irrigating solutions. This is probably due to its bactericidal and fungicidal properties: cetrimide does not affect the ability of demineralization of citric acid and EDTA solutions. Is important to establish that if a high demineralization of root canal dentin is required, EDTA is considered the gold standard in endodontics. Further clinical and in vitro studies are needed to verify if a higher amount of $\mathrm{Ca} 2+$ extracted from root dentin can be useful or harmful. Citric acid values of demineralization are considerably higher than EDTA values, in presence or absence of cetrimide.

\section{Conclusion}

Under the experimental conditions and restricting to the irrigants considered in this investigation, to obtain an efficient decalcifying action on dentin (and subsequently the smear layer removal) and to facilitate the biomechanical procedures, citric acid based irrigants can be applied. Moreover the presence of cetrimide in the irrigating solutions does not improve the extraction of $\mathrm{Ca} 2+$ from root dentine and it could be considered useful to complete antibacterial activity of irrigating solutions.

5. McComb D, Smith DC. A preliminary scanning electron microscopic study of root canal after endodontic procedures. J Endod. 1975 Jul;1(7):238-42.

6. Scelza MFZ, Teixeira AM, Scelza P. Decalcifyng effect of EDTAT, 10\% citric acid, and 17\% EDTA on root canal dentin. Oral Surg Oral Med Oral Pathol Oral Radiol Endod. 2003 Feb;95(2):234-6.

7. Hülsmann M, Heckendorff M, Schäfers F. Comparative in-vitro evaluation of three chelator pastes. Int Endod J. 2002 Aug;35(8):668-79.

8. O'Connell MS, Morgan LA, Beeler WJ, Baumgartner JA. A comparative study of smear layer removal using different salts of EDTA. J Endod. 2000 Dec;26(12):739-43. 
9. Scelza MFZ, Daniel RLDP, Santos EM, Jaeger MMM. Cytotoxic effects of $10 \%$ citric acid and EDTA-T used as root canal irrigants: an in vitro analysis. J Endod. 2001 Dec;27(12):741-3.

10. Segura-Egea JJ, Jimenez-Rubio A, Rios-Santos JV, VelascoOrtega E, Calvo-Gutierrez JR. In vitro inhibitory effect of EGTA on macrophage adhesion: endodontic implications. J Endod. 2003 Mar;29(3):211-3.

11. Calt S, Serper A. Smear layer removal by EGTA. J Endod. 2000 Aug;26(8):459-61.

12. Garberoglio R, Becce C. Smear layer removal by root canal irrigants. A comparative scanning electron microscopic study. Oral Surg Oral Med Oral Pathol Oral Radiol Endod. 1994 Sep;78(3):359-67.

13. Machado-Silveiro LF, González-López S, González-Rodríguez MP. Decalcification of root canal dentine by citric acid, EDTA and sodium citrate. Int Endod J. 2004 Jun;37(6):365-9.

14. Perez-Heredia M, Ferrer-Luque CM, Gonzalez-Rodriguez MP. The effectiveness of different acid irrigating solutions in root canal cleaning after hand and rotary instrumentation. J Endod. 2006 Oct;32(10):993-7.
15. Giardino L, Ambu E, Becce C, Rimondini L, Morra M. Surface tension comparison of four common root canal irrigants and two new irrigants containing antibiotic. J Endod. 2006 Nov;32(11):1091-3.

16. Poggio C, Dagna A, Chiesa M, Bianchi S, Arciola CR, Visai L, et al. SEM evaluation of the root canal walls after treatment with Tetraclean. Int J Artif Organs. 2010 Sep;33(9):660-6.

17. Arias-Moliz MT, Ferre-Luque CM, Gonzalez-Rodriguez MP, Valderrama MJ Baca P. Eradication of Enterococcus faecalis biofilms by Cetrimide and chlorhexidine. J Endod. 2010 Jan;36(1):87-90.

18. Leow N, Abbott P, Castro Salgado J, Firth L. Evaluation of smear layer removal by bicarbonate soda, ethylenediamine tetraacetic acid with cetrimide and sodium hypochlorite with a new model. Aust Endod J. 2012 Dec;38(3):107-12.

19. Spanò JC, Silva R, Guedes D, Sousa-Neto M, Estrela C, Pécora J. Atomic absorption spectrometry and scanning electron microscopy evaluation of concentration of calcium ions and smear layer removal with root canal chelators. J Endod. 2009 May;35(5):727-30.

20. Sterrett JD, Delaney B, Rizkalla A, Hawkins CH. Optimal citric acid concentration for 3 dentinal demineralization. Quintessence Int. 1991 May;22(5):371-5. 